\title{
TMS MEMBER NEWS
}

\section{Share the Good News!}

Contact Kaitlin Calva, JOM: The Magazine Managing Editor, at kcalva@tms.org to share your professional accomplishments. Please note that only news submitted by current TMS members will be considered.

\section{Early Career TMS Members Build Leadership Skills}

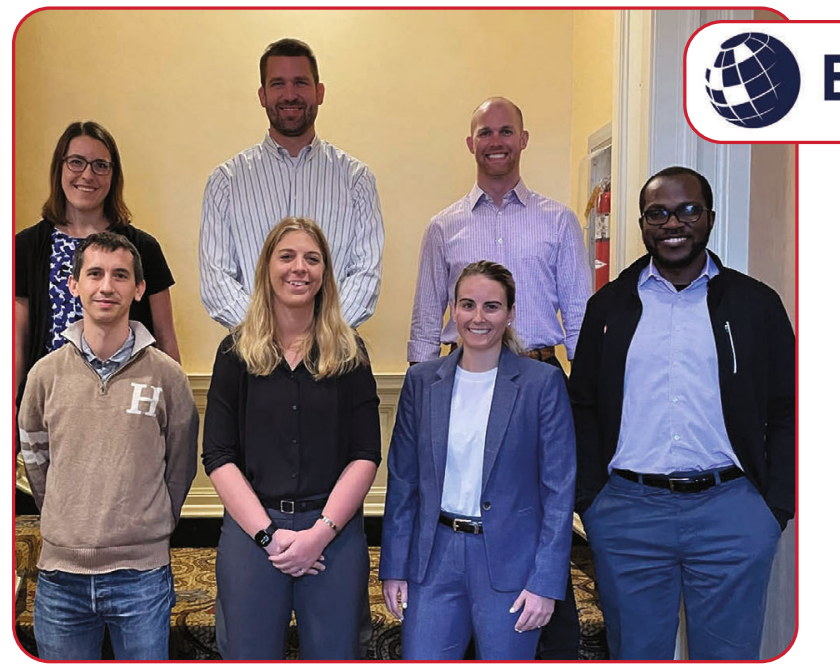

\section{Emerging Leaders Alliance}

also found value in attending the program. "The Emerging Leaders Alliance conference gave me the opportunity to expand my professional network with like-minded individuals from across the industry." she said. "The leadership training was very insightful. I plan to apply these insights to my professional interactions at work, and I believe these skills will help me become a more effective leader moving forward."

Echoing the sentiments of her colleagues, Joy Gockel, Colorado School of Mines and 2021 TMS Structural Materials Division Young Leader, found value in the training provided by the ELA program. In particular, she appreciated "the opportunity to grow my non-technical skills needed for engineering and

The TMS contingent of the 2021 Emerging Leaders Alliance conference. Front row, left to right: Aurelien Perron, Lawrence Livermore National Laboratory; Danielle Jencks, Pratt \& Whitney; Allie (Alexandra) Anderson, Gopher Resource; and Chukwunwike lloeje, Argonne National Laboratory. Back row, left to right: Joy Gockel, Colorado School of Mines; Jonathan Raush, University of Louisiana at Lafayette; and Charles Fisher, Naval Surface Warfare Center - Carderock.

"The Emerging Leaders Alliance (ELA) was extremely helpful in understanding my personal leadership style, both its strengths and areas to grow. Using that knowledge will help me develop as a scientist and better support my team," said Charles Fisher, Naval Surface Warfare Center - Carderock, one of seven TMS members to attend the most recent ELA conference, held September 26-29, 2021, in Pittsburgh, Pennsylvania.

Each year, this program provides interdisciplinary training for future leaders of the science and engineering community. This high-quality training aims to equip early career individuals with the skills needed to guide the professions and address the needs of people in the 21st century. TMS is one of nine ELA partner societies, and attendance for TMS members was possible through the support of the TMS Foundation.

Alexandra Anderson, Gopher Resource and 2021 TMS Extraction \& Processing Division Young Leader, science leadership through understanding my own leadership style, the style of others, and building a successful team. I am looking forward to applying these skills at my university and towards continued involvement in TMS volunteer activities."

If you are interested in enhancing your own scientific leadership skills, TMS is now accepting applications for the next ELA conference, scheduled for September 2022. Applicants must be TMS members, typically ages $24-40$, with rising or current leadership positions within their organizations. To apply for a seat at the 2022 conference, please send a letter of interest, one or two letters of recommendation, and a resume or curriculum vitae to Deborah Hixon, TMS Awards Program Administrator, at hixon@tms.org. The deadline to apply for the 2022 program is May 15, 2022.

It is clear through the stories of the TMS members featured here that this training provides a unique opportunity to interact across disciplines and obtain foundational, executive-level knowledge. More established TMS members can support future leaders of TMS by donating to the TMS Foundation. Any level of contribution helps ensure that the future leaders of our community have access to this valuable program, in addition to other Foundation initiatives geared toward developing early career professionals. Visit wWww.TMSFoundation.org to learn more and to make a donation. 


\section{Journal of Electronic Materials Seeking Submissions for New Topical Collection}

The Journal of Electronic Materials is planning a new topical collection, Synthesis and Advanced Characterization of Magnetic Oxides. Article

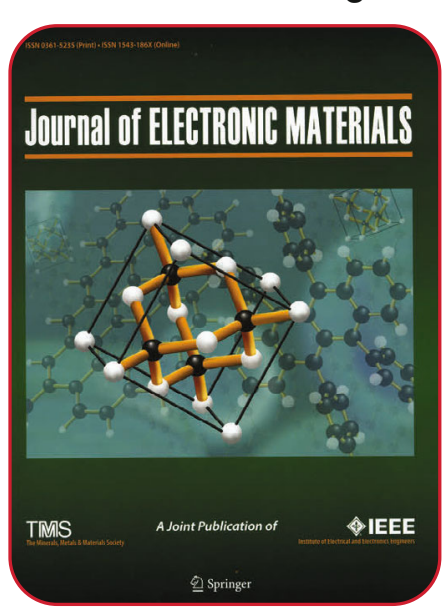

submissions are due

February 28, 2022.

The objective of this collection is to publish articles focusing on magnetic oxides that are expected to be beneficial to both experts and the wider scientific community working in the field of materials science. Contributions in the following themes and topics are invited for submission:

- Synthesis and fabrication of magnetic oxides

- Developmental of oxides with magnetic functionality and other important functional behavior
- Computational methods and their applications to magnetic oxides

- Magnetic and phase transformation studies in magnetic oxides using synchrotron $\mathrm{x}$-ray methods, such as $\mathrm{x}$-ray absorption spectroscopy

- Imaging methods such as magnetic force microscopy and x-ray near edge structureimaging

- Magnetic oxides for spintronics

- Magnetic oxides for energy and environmental applications

- Magnetic oxides for biomedical applications

Guest editors for this collection include Manish Kumar, Pohang Accelerator Laboratory, South Korea; R.C. Srivastava, G B Pant University of Agriculture and Technology, India; Shalendra Kumar, King Faisal University, Saudi Arabia; and Jitendra Pal Singh, Pohang Accelerator Laboratory, South Korea.

Articles for this collection can be submitted at www.editorialmanager.com/jems. Once there, select article type, "2022 Magnetic Oxides." For author instructions and additional details on the journal, visit www.springer.com/11664.

\section{TMS Announces New Study on Artificial Intelligence}

With interest in artificial intelligence (Al) growing rapidly, TMS launched the Employing Artificial Intelligence to Accelerate Development and Implementation of Materials and Manufacturing Innovations science and technology accelerator report in 2021. While TMS is leading the work on the study, funding comes from the National Institute of Standards and Technology (NIST) and the Office of Naval Research (ONR). The purpose of this project is to support innovative materials and manufacturing breakthroughs that are enabled by $\mathrm{Al}$ and will accelerate the development of and reduce the costs of new materials, processes, and products.

The final report, scheduled for release in April 2022, will include the following key takeaways:

- The application domains of most promise will be scoped and prioritized.

- For the identified high priority areas, concrete recommendations on key milestones and implementation pathways will be provided.

This study is being conducted by a team of 11 experts, chaired by Elizabeth Holm, Carnegie Mellon University. The other members of the study team are:

- Surya Kalidindi, Georgia Institute of Technology

- Adam Kopper, Mercury Marine

- Kenneth A. Loparo, Case Western Reserve University

- Benji Maruyama, U.S. Air Force Reserach

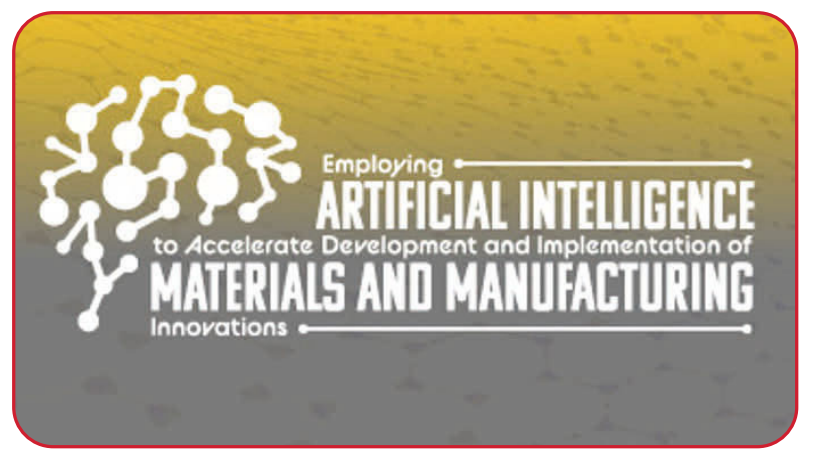

Laboratory Materials and Manufacturing Directorate

- Elsa Olivetti, Massachusetts Institute of Technology

- Kristin Persson, Lawrence Berkeley National Laboratory and the University of California, Berkeley

- Taylor Sparks, University of Utah

- Aarti Singh, Carnegie Mellon University

- Francesca Tavazza, National Institute of Standards and Technology

- Christopher Wolverton, Northwestern University

Visit www.tms.org/AIStudy to learn more about each of the team members and to sign up to receive updates about this study, including a notification when the free report is available. 
TMS Members Honored with 2021 MetSoc Awards

Congratulations to the following TMS members for being named recipients of the Metallurgy and Materials Society (MetSoc) of the Canadian Institute of Mining, Metallurgy, and Petroleum (CIM) 2021 awards. These awards were presented at the Conference of Metallurgists (COM) 2021: Advances in Metallurgy and Materials Engineering, celebrating the 60th anniversary of the MetSoc annual meeting, in August 2021

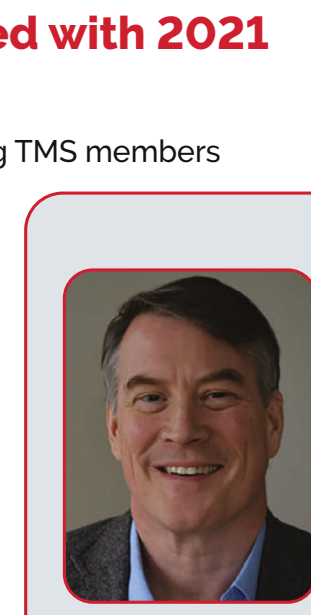

Boyd R. Davis

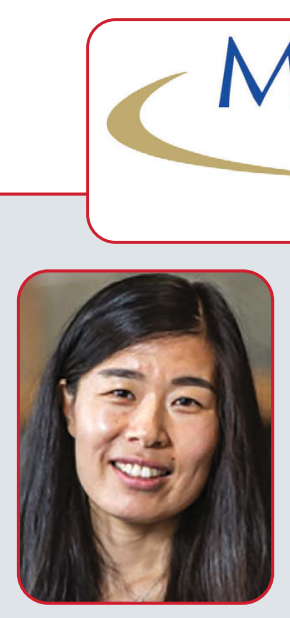

Wenying Liu

\section{MET SOC}
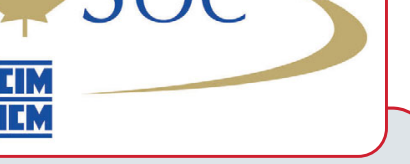

\section{MetSoc Award for Research Excellence Sponsored by Rio Tinto}

Boyd R. Davis, KPM

TMS Member since 1999

The MetSoc Award is the premier award for contribution to the metallurgy or materials field by a MetSoc member academic or research scientist in any Canadian research laboratory or Canadian university. The award recognizes a lifetime contribution in teaching and research or outstanding individual work resulting in a significant breakthrough in the metallurgy or materials practices.

Citation: For being at the forefront of research, opening a laboratory, and forming many young professionals.

MetSoc Brimacombe Award Wenying Liu, University of British Columbia TMS member since 2016

The Brimacombe Award is to recognize early-career MetSoc member achievers who have made noteworthy contributions in any of the scientific and technological disciplines relevant to MetSoc.

Citation: For early and important contributions to the science and engineering of hydrometallurgical processes.

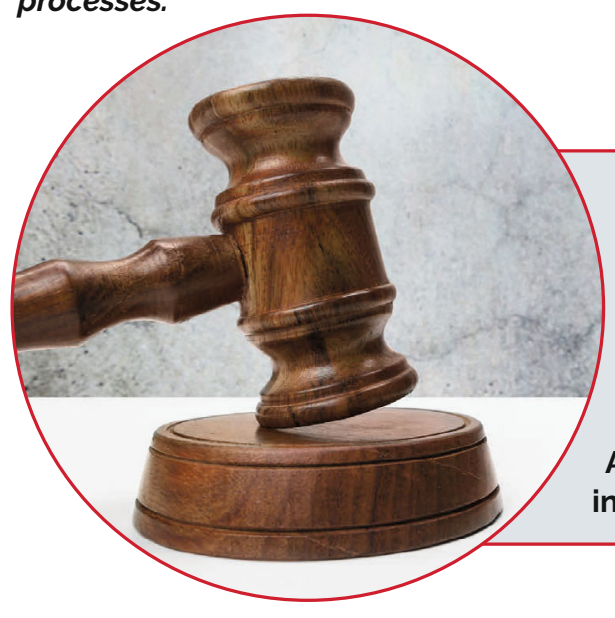

Announcing the 2022 TMS Meeting of the Membership and Open Board of Directors Meeting

The Minerals, Metals \& Materials Society, Inc., in accordance with its bylaws (Article II, Section 2.6, and Article III, Section 3.7) will hold the 2022 Annual Meeting of the Membership with Open Board of Directors Meeting, on Thursday, March 3, 2022, at 8 a.m. (PT) at the Anaheim Marriott, during the TMS 2022 Annual Meeting \& Exhibition in Anaheim, California.

MetSoc Distinguished Materials Scientist Award Mathieu Brochu, McGill University TMS member since 1999

This award recognizes highly significant contributions in the field of materials engineering. Citation: In recognition of significant and novel contributions to a broad range of Advanced Materials Processing.

CIM Fellowship

Boyd R. Davis, KPM

TMS member since 1999

Mihaiela Isac, McGill University

For outstanding continuous contributions to CIM and/or the mining, metallurgical, and petroleum industries

\section{Pyrometallurgy Best Paper Award}

Petri Latostenmaa, Boliden Harjavalta

TMS member since 2012

Pekka Taskinen, Aalto University

TMS member since 1992

The Pyrometallurgy Best Paper Award was established by the Pyrometallurgy Section to recognize the best paper on this topic published in either the CIM Magazine, the Canadian Metallurgical Quarterly, or the Conference Proceedings from the previous year. 